\title{
Effect of Intensive Integrative Therapies on Pain, Disability and Quality of Life in Patients with Osteoarthritis Knees: A Comparative Observational Study
}

\author{
Monika Gautam ${ }^{1 *}$, Apar Saoji ${ }^{1}$, Harish Babu${ }^{1}$ and Vaidya Rohit Mehta ${ }^{2}$ \\ ${ }^{1} S$-vyasa university, Jigani, India
}

${ }^{2}$ Kayakalp, Himachal Pradesh, India

*Corresponding author: Dr. Monika Gautam, BNYS, MD Scholar, S-vyasa university, Jigani, Bangalore, India

Received: 毕 December 12, 2019

Published: 制 December 18, 2019

\begin{abstract}
Objective: To assess the differential effect of intensive yoga, yoga and naturopathy and yoga and Ayurveda management for Osteoarthritis of knees Design: Pre-post comparative study

Participants: Ninty-five individual prediagnosed with knee osteoarthritis according to ACR guidelines aged between 30-75 years were randomized into three groups, i.e., Yoga $(n=36)$, yoga and Naturopathy $(n=30)$, Yoga and Ayurveda $(n=29)$. All three group received their respective intervention for 1 week at arogyadhama, prashanti kutiram, S-VYASA.

Outcome measures: The primary outcome variables were visual analog scale (VAS) for pain on activity, Western Ontario and McMaster Universities Secondary Osteoarthritis index (WOMAC) and secondary outcome variables were anthropometric measurements and 6 min walk test were measured on day 1 and day 7.

Results: There was significant reduction in VAS scale on activity in yoga group $(\mathrm{p}<0.001)$, whereas in Ayurveda group showed significant improvement in stiffness $(\mathrm{p}<0.001)$, and significant reduction in weight and pain on rest $(\mathrm{p}<0.001)$ was in naturopathy group after 7 days of intervention.

Conclusion: IAYT practices combined with other therapies had better effect than alone IAYT. There were significant changes seen within groups.
\end{abstract}

Keywords: Knee Osteoarthritis; Integrative Approach of Yoga Therapy (IAYT); VAS; WOMAC; Ayurveda; Naturopathy

\section{Introduction}

Movement is a medicine for creating change in a person's physical, emotional, and mental states. Disease is the destroyer of health wealth and mind. Lack of movement of knees leads to the later. The most common of lack of movement is Osteoarthritis (OA) OA knee mainly occurs in elders and middle age people and is more common among women and overweight subjects. The symptoms include pain, stiffness and decreased range of motion (ROM), which result in limited activity and reduced quality of life. The prevalence increases with age, and by the age of 65 , approximately 80 percent of the US population is affected. It is the second most common rheumatological problem and most frequent joint disease with prevalence of $22 \%$ to $39 \%$ in India OA is a heterogenous disease, involving complex and interacting mechanical, biological, biochemical, molecular and enzymatic feedback loops with cartilage degeneration as the common, final event [1] despite this degeneration, $\mathrm{OA}$ is an active process and a network of mechanisms reacting to stress or injury on the joint. All joint features are affected in OA [2]. Structural changes include cartilage fibrillation, degeneration of articular cartilage, thickening of subchondral bone, osteophyte formation, synovial inflammation, degeneration of ligaments and meniscus, hypertrophy of joint capsule, cellular and molecular changes in nerves, as well as changes to periarticular muscle, bursa, fat pads [3]. The loss of cartilage and modifications to bone and synovial membrane contribute to an unfavorable biomechanical environment which increases stress on the joint and furthers the progression of cartilage degradation [4]. Non-steroidal anti-inflammatory drugs (NSAIDs), including cyclo-oxygenase II inhibitors and non-opioids analgesics such as acetaminophen have 
been the most popular method of managing pain in musculoskeletal tissues. Tradational System of medicine like Ayurveda, Naturopathy and Yoga also specify the symptoms and mode of treatment. So a observational study was planned to understand the effect of this traditional system of medicine.

\section{Aim of the Study}

a. To study the differential effect of three Indian systems of medicine on the outcome of OA knee management

\section{Objective of the Study}

a. To assess the differential effect of intensive yoga, yoga and naturopathy and yoga and Ayurveda management for Osteoarthritis of knees on pain and stiffness.

b. To assess the differential effect of intensive yoga, yoga and naturopathy and yoga and Ayurveda management for Osteoarthritis of knees on physical functions.

To assess the differential effect of intensive yoga, yoga and naturopathy and yoga and Ayurveda management for Osteoarthritis of knees on anthropometric measurements.

\section{Material and Methods}

\section{Source of data}

A total of 95 participants aged 30-75 years, were registered from Arogyadhama, a home-based health centre, S- VYASA, bangalore.

\section{Sample size}

The sample size was calculated with G-power software by fixing the alpha at 0.05 powered at 0.8 and an effect size of 0.71 based on the mean and SD of an earlier study.

\section{Inclusion criteria}

The inclusion criteria were patients clinically/radiologically diagnosed with mild to moderate OA knees according to American college of rheumatology (ACR) guidelines and with associated comorbidities were included in the study.

\section{Exclusion criteria}

Patients with severe OA knees, rheumatoid arthritis, autoimmune diseases, malignancies, knee surgery or kneearthroscopy and knee pain caused due to congenital dysplasia were excluded.

\section{Ethical consideration}

The study was approved by the Institutional Ethics Committee of S-VYASA University (approval letter no: RES/IECSVYASA/107/2017 dated 23rd October 2017). Signed informed consent was obtained from all the participants included in this study.

\section{Design}

Participants were randomly divided into three groups, i.e., Yoga alone, Yoga and Naturopathy, Yoga and Ayurveda group. All three groups underwent intervention of Integrative approach of yoga therapy (IAYT) and respective therapies for 6 days and assessments and treatment plans for participants were discussed with in-charge doctor and therapists. All groups continued their medication as per prescription.

\section{Grouping and posology}

Three groups pre-post comparative study.

Group A: Table 1 Standalone Yoga group

Table 1: Time table.

\begin{tabular}{|c|c|}
\hline Time & Schedule \\
\hline $5: 30 \mathrm{AM}$ & Om meditation \\
\hline 6:00 AM & Yogasana Practice \\
\hline 7:00 AM & Breakfast \\
\hline 8:00 AM & Maitrimilan \\
\hline 9:00 AM & Parameters \& Counselling \\
\hline 10:00 AM & Pranayama \\
\hline 11:00 AM & Yogasana Practice \\
\hline 12:00 PM & Lecture \\
\hline 1:00 PM & Lunch \\
\hline 2:00 PM & Rest \\
\hline 3:00 PM & Cyclic Meditation \\
\hline 4:00 PM & Yogasana Practice \\
\hline 5:00 PM & Malt \& Tuning to Nature \\
\hline 6:00 PM & Bhajana \\
\hline $6: 30 \mathrm{PM}$ & Trataka, Mind Sound Resonance Technique (MSRT) \\
\hline $7: 30 \mathrm{PM}$ & Dinner \\
\hline $8: 15$ PM & Happy Assembly \\
\hline 10:00 PM & Bedtime \\
\hline
\end{tabular}

Group B: Table 2 Integrative Yoga and Ayurveda group

Table 2: Time table.

\begin{tabular}{|c|c|}
\hline Time & Schedule \\
\hline $5: 30 \mathrm{AM}$ & Om meditation \\
\hline $6: 00 \mathrm{AM}$ & Yogasana Practice \\
\hline 7:00 AM & Breakfast \\
\hline 8:00 AM & Maitrimilan \\
\hline 9:00 AM & Parameters \& Counselling \\
\hline $10: 00 \mathrm{AM}$ & Ayurveda treatment \\
\hline 11:00 AM & Yogasana practice \\
\hline $12: 00 \mathrm{PM}$ & Lecture \\
\hline $1: 00 \mathrm{PM}$ & Pranayama \\
\hline 2:00 PM & Rest \\
\hline 3:00 PM & Cyclic Meditation \\
\hline 4:00 PM & Yogasana Practice \\
\hline 5:00 PM & Malt \& Tuning to Nature \\
\hline 6:00 PM & Bhajana \\
\hline $6: 30 \mathrm{PM}$ & Trataka, Mind Sound Resonance Technique (MSRT) \\
\hline 7:30 PM & Dinner \\
\hline 8:15 PM & Happy Assembly \\
\hline 10:00 PM & BedTime \\
\hline
\end{tabular}

Group C: Table 3 Integrative Yoga and Naturopathy group 
Table 3: Time table.

\begin{tabular}{|c|c|}
\hline Time & Schedule \\
\hline $5: 30 \mathrm{AM}$ & Om meditation \\
\hline $6: 00 \mathrm{AM}$ & Yogasana Practice \\
\hline $7: 00 \mathrm{AM}$ & Breakfast \\
\hline 8:00 AM & Maitrimilan \\
\hline $9: 00 \mathrm{AM}$ & Parameters \& Counselling \\
\hline $10: 00 \mathrm{AM}$ & Naturopathy treatment \\
\hline $11: 00 \mathrm{AM}$ & Lunch \\
\hline $12: 00 \mathrm{PM}$ & Lecture \\
\hline $1: 00 \mathrm{PM}$ & Pranayama \\
\hline $2: 00 \mathrm{PM}$ & Rest \\
\hline $3: 00 \mathrm{PM}$ & Cyclic Meditation \\
\hline $4: 00 \mathrm{PM}$ & Yogasana Practice \\
\hline $5: 00 \mathrm{PM}$ & Malt \& Tuning to Nature \\
\hline $6: 00 \mathrm{PM}$ & Bhajana \\
\hline $6: 30 \mathrm{PM}$ & Trataka, Mind Sound Resonance Technique (MSRT) \\
\hline 7:30 PM & Dinner \\
\hline 8:15 PM & Happy Assembly \\
\hline $10: 00 \mathrm{PM}$ & Bed Time \\
\hline
\end{tabular}

\section{Assessment criteria}

Primary outcome variables

a) Visual analog scale for pain on activity

b) WOMAC Indian version

c) 6 min walking distance test - The subjects were asked to walk on a flat surface for 6 minutes and the distance covered was expressed in meters.

\section{Anthropometric measurements}

a) Height: It was measured with stadiometer in centimeters $(\mathrm{cm})$, and later converted into meters.

b) Weight: Weight was measured using research grade electronic weighing scale.

c) BMI: By using formula, weight in $\mathrm{kg} /$ height in meter2, calculated the body mass

index of every individual.

\section{Observations}

Table 4

Table 4: Observations.

\begin{tabular}{|c|c|c|c|c|}
\hline & Ayurveda & Naturopathy & Yoga & Total \\
\hline Sample size & $\mathbf{n = 2 9}$ & $\mathbf{n = 3 0}$ & $\mathbf{n = 3 6}$ & $\mathbf{N}=\mathbf{9 5}$ \\
\hline Age & $61.79 \pm 8.85$ & $61.47 \pm 7.99$ & $61 \pm 7.62$ & $61.39 \pm 8.05$ \\
\hline Male/Female & 20 -Sep & $22-$ Aug & Mar-33 & $20 / 75$ \\
\hline Height $(\mathrm{cm})$ & $155.48 \pm 8.96$ & $160.5 \pm 10.6$ & $155 \pm 2.83$ & $156 \pm 1.41$ \\
\hline Weight $(\mathrm{kg})$ & $73.24 \pm 12.03$ & $76.90 \pm 14.99$ & $71.23 \pm 11.63$ & $60.65 \pm 11.81$ \\
\hline
\end{tabular}

\section{Results}

\section{Recapitulation}

In the current study, variables were taken at baseline and following one week of intensive yoga, yoga and Ayurveda and yoga and naturopathy therapies. The primary outcome variable was pain pain assessed through Visual Analogue Scale (VAS) while resting, walking on plane surface, climbing stairs up and down as well as WOAMC scores. The secondary assessments included anthropometric measurements; and 6 min walking distance. We also recorded the vital parameters such as systolic and diastolic

\section{Yoga and naturopathy group}

Table 5: With-in group comparison changes in yoga and ayurveda group.

\begin{tabular}{|c|c|c|c|c|}
\hline \multicolumn{2}{|c|}{ Variables } & t & df & Sig. (2-tailed) \\
\hline Pair 1 & WT-PRE - WT-POST & 5.143 & 28 & $* * * .000$ \\
\hline Pair 2 & BMI-PRE - BMI-POST & 4.898 & 28 & $* * .000$ \\
\hline Pair 3 & SYS-PRE - SYS-POST & 1.011 & 28 & 0.32 \\
\hline Pair 4 & DIA-PRE - DIA-POST & 1.914 & 28 & 0.066 \\
\hline Pair 5 & PR-PRE - PR-POST & -1.02 & 28 & 0.317 \\
\hline Pair 6 & RR-PRE - RR-POST & 1.1 & 28 & 0.281 \\
\hline Pair 7 & 6-PRE - 6-POST & -5.259 & 28 & $* * * .000$ \\
\hline
\end{tabular}

blood pressure, pulse rate and respiratory rates at baseline and at the end of one-week intervention for all three groups.

\section{Yoga and ayurveda group}

Within group comparison revealed that as compared to the baseline following variables showed significant improvement in weight, body mass index, 6-min walk test, WOMAC global score, WOMAC-pain, stiffness and physical functioning, visual analog score on rest, walking, climbing up and down. The values of within group comparison through paired sample $t$ test are mentioned in Table 4. 


\begin{tabular}{|c|c|c|c|c|}
\hline Pair 8 & WGS-PRE - WGS-POST & 4.992 & 28 & ${ }^{* * *} .000$ \\
\hline Pair 9 & PAIN-PRE - PAIN-POST & 5.809 & 28 & ${ }^{* * *} .000$ \\
\hline Pair 10 & STF-PRE - STF-POST & 3.36 & 28 & ${ }^{* *} .002$ \\
\hline Pair 11 & PF-PRE - PF-POST & 4.243 & 28 & ${ }^{* * *} .000$ \\
\hline Pair 12 & VAS-PRE - VAS-POST & 2.806 & 28 & ${ }^{* *} .009$ \\
\hline Pair 13 & VAS-WK-Pre - VAS-WK-Post & 4.105 & 28 & ${ }^{* * *} .000$ \\
\hline Pair 14 & VAS-UP-Pre - VAS-UP-Post & 5.359 & 28 & ${ }^{* *} .000$ \\
\hline Pair 15 & VAS-DOW - VAS-DW & 4.914 & & $* * * .000$ \\
\hline
\end{tabular}

Within group comparison revealed that as compared to the baseline following variables showed significant improvement in weight, body mass index, systolic blood pressure, respiratory rate 6-min walk test, WOMAC global score, WOMAC- pain, stiffness and physical functioning, visual analog scale on rest, walking and climbing up and down. The values of within group comparison through paired sample t test are given in Table 5.

\section{Yoga group}

Within group comparison revealed that as compared to the baseline following variables showed significant changes in weight, Diastolic blood pressure, Pulse rate, 6 MIN walking distance, WOMAC global scores, WOMAC-pain, stiffness and physical functioning, visual analog score on rest, walking and climbing up and down. The values of within-group comparisons through the paired samples t-test are mentioned in Table 6.

Table 6: Within group changes in yoga and naturopathy group.

\begin{tabular}{|c|c|c|c|c|}
\hline \multicolumn{2}{|c|}{ Variables } & \multirow{2}{*}{$\begin{array}{c}\mathbf{t} \\
8.21\end{array}$} & \multirow{2}{*}{$\begin{array}{l}\text { df } \\
29\end{array}$} & \multirow{2}{*}{$\begin{array}{c}\text { Sig. (2-tailed) } \\
*^{* *} .000\end{array}$} \\
\hline Pair 1 & WT-PRE - WT-POST & & & \\
\hline Pair 2 & BMI-PRE - BMI-POST & 8.137 & 29 & $* * * .000$ \\
\hline Pair 3 & SYS-PRE - SYS-POST & 3.313 & 29 & $* * .002$ \\
\hline Pair 4 & DIA-PRE - DIA-POST & 1.058 & 29 & 0.299 \\
\hline Pair 5 & PR-PRE - PR-POST & 1.705 & 29 & 0.099 \\
\hline Pair 6 & RR-PRE - RR-POST & 2.269 & 29 & $* 031$ \\
\hline Pair 7 & 6-PRE - 6-POST & -3.844 & 29 & ${ }^{* * *} .001$ \\
\hline Pair 8 & WGS-PRE - WGS-POST & 4.987 & 29 & $* * * .000$ \\
\hline Pair 9 & PAIN-PRE - PAIN-POST & 4.469 & 29 & $* * * .000$ \\
\hline Pair 10 & STF-PRE - STF-POST & 3.223 & 29 & $* * .003$ \\
\hline Pair 11 & PF-PRE - PF-POST & 4.695 & 29 & ${ }^{* * *} .000$ \\
\hline Pair 12 & VAS-PRE - VAS-POST & 4.038 & 29 & $* * * .000$ \\
\hline Pair 13 & VAS-WK - VAS-WK & 4.793 & 29 & ***.000 \\
\hline Pair 14 & VAS-UP - VAS-UP & 6.185 & 29 & $* * * .000$ \\
\hline Pair 15 & VAS-DOW - VAS-DW & 5.396 & 29 & ***.000 \\
\hline
\end{tabular}

Table 7: Within group changes in yoga group.

\begin{tabular}{|c|c|c|c|c|}
\hline & & $\mathbf{t}$ & df & Sig. (2-tailed) \\
\hline Pair 1 & WT-PRE - WT-POST & 3.44 & 35 & $* * .002$ \\
\hline Pair 2 & BMI-PRE - BMI-POST & -0.402 & 35 & 0.69 \\
\hline Pair 3 & SYS-PRE - SYS-POST & 1.659 & 35 & 0.106 \\
\hline Pair 4 & DIA-PRE - DIA-POST & 2.556 & 35 & $* .015$ \\
\hline Pair 5 & PR-PRE - PR-POST & 2.181 & 35 & $* .036$ \\
\hline Pair 6 & RR-PRE - RR-POST & 0.44 & 35 & 0.663 \\
\hline Pair 7 & 6-PRE - 6-POST & -2.47 & 35 & $* .019$ \\
\hline Pair 8 & WGS-PRE - WGS-POST & 3.86 & 35 & $* * * .000$ \\
\hline Pair 9 & PAIN-PRE - PAIN-POST & 3.812 & 35 & ***.001 \\
\hline Pair 10 & STF-PRE - STF-POST & 3.416 & 35 & $* * .002$ \\
\hline Pair 11 & PF-PRE - PF-POST & 3.497 & 35 & ***.001 \\
\hline Pair 12 & VAS-PRE - VAS-POST & 4.12 & 35 & ${ }^{* * *} .000$ \\
\hline Pair 13 & VAS-WK - VAS-WK & 5.718 & 35 & ***.000 \\
\hline
\end{tabular}

Citation: Monika G, Apar S, Harish B, Vaidya Rohit M. Effect of Intensive Integrative Therapies on Pain, Disability and Quality of Life in Patients with Osteoarthritis Knees: A Comparative Observational Study. Orthop \& Spo Med Op Acc J 3(3)- 2019. OSMOAJ.MS.ID.000161. D0I: 10.32474/OSMOAJ.2019.03.000161. 


\begin{tabular}{|l|c|c|c|}
\hline Pair 14 & VAS-UP - VAS-UP & 8.63 & 35 \\
\hline Pair 15 & VAS-DOW - VAS-DW & 7.657 .000 & 35 \\
\hline
\end{tabular}

\section{Abbreviations}

WT: Weight, DBP: Diastolic Blood Pressure, PR: Pulse Rate, WGS: WOMAC Global Score, STF: Stiffness, PF: Physical Functioning, VAS: Visual Analog Scale, WK: Walking, DW: Down, BMI: Body Mass Index, SBP: Systolic Blood Pressure, RR: Respiratory Rate, WOMAC

Table 8: Results of the study.
Table 8 presents the changes in all three groups at baseline and at the end of one week. None of the variables between groups were found significant both at baseline and following the one-week intervention duration.

\begin{tabular}{|c|c|c|c|c|c|c|c|c|c|}
\hline \multirow[t]{2}{*}{ Variable } & \multicolumn{3}{|c|}{ Ayurveda $(n=29)$} & \multicolumn{3}{|c|}{ Naturopathy $(n=30)$} & \multicolumn{3}{|c|}{ Yoga $(n=36)$} \\
\hline & Pre & Post & $\%$ Change & Pre & Post & $\%$ Change & Pre & Post & \% Change \\
\hline Weight in Kg & $73.24 \pm 12.03$ & $72.01 \pm 11.56^{* * *}$ & 1.68 & $76.90 \pm 14.99$ & $74.99 \pm 14.45^{* * *}$ & 2.48 & $71.23 \pm 11.63$ & $70.05 \pm 11.13^{* *}$ & 1.65 \\
\hline BMI & $30.36 \pm 4.49$ & $29.89 \pm 4.31^{* * *}$ & 1.54 & $31.19 \pm 4.81$ & $30.48 \pm 4.85^{* * *}$ & 2.28 & $28.36 \pm 4.55$ & $28.55 \pm 4.92$ & -0.67 \\
\hline $\begin{array}{l}\text { SBP in } \\
\mathrm{mmHg}\end{array}$ & $128.21 \pm 12.52$ & $124.83 \pm 16.46$ & 2.63 & $133.80 \pm 15.81$ & $128.07 \pm 14.18^{* *}$ & 4.28 & $127.78 \pm 14.60$ & $123.56 \pm 13.90$ & 3.3 \\
\hline $\begin{array}{l}\text { DBP in } \\
\mathrm{mmHg}\end{array}$ & $79.45 \pm 9.41$ & $75.93 \pm 7.83$ & 4.43 & $79.87 \pm 9.71$ & $78.13 \pm 7.96$ & 2.17 & $78.11 \pm 9.22$ & $73.67 \pm 8.38^{*}$ & 5.68 \\
\hline PR in bpm & $75.90 \pm 8.20$ & $77.66 \pm 8.02$ & -2.32 & $79.13 \pm 10.04$ & $76.10 \pm 7.13$ & 3.83 & $76.47 \pm 6.88$ & $73.50 \pm 6.10^{*}$ & 3.88 \\
\hline RR in cpm & $17.55 \pm 3.11$ & $16.83 \pm 3.22$ & 4.1 & $19.23 \pm 3.36$ & $17.77 \pm 2.61^{*}$ & 7.59 & $18.06 \pm 2.96$ & $17.81 \pm 3.43$ & 1.38 \\
\hline WGS & $55.93 \pm 19.70$ & $44.72 \pm 16.81^{* * *}$ & 20.04 & $57.13 \pm 20.83$ & $43.87 \pm 19.46^{* * *}$ & 23.21 & $55.00 \pm 18.32$ & $44.94 \pm 21.09^{* * *}$ & 18.29 \\
\hline $\begin{array}{l}\text { WOMAC- } \\
\text { Pain } \\
\text { Subscale }\end{array}$ & $7.55 \pm 3.57$ & $5.59 \pm 3.23^{* * *}$ & 25.96 & $8.43 \pm 3.74$ & $6.23 \pm 3.31^{* * *}$ & 26.09 & $8.03 \pm 3.53$ & $6.08 \pm 4.19^{* * *}$ & 24.28 \\
\hline $\begin{array}{l}\text { WOMAC- } \\
\text { stiffness }\end{array}$ & $3.21 \pm 2.09$ & $2.34 \pm 1.58^{* *}$ & 27.1 & $3.63 \pm 2.29$ & $2.80 \pm 1.77^{* *}$ & 22.86 & $3.28 \pm 1.58$ & $2.44 \pm 1.71^{* *}$ & 25.61 \\
\hline WOMAC-PF & $45.17 \pm 15.36$ & $36.79 \pm 13.54^{* * *}$ & 18.55 & $44.43 \pm 15.38$ & $34.80 \pm 15.68^{* * *}$ & 21.67 & $43.69 \pm 14.45$ & $36.53 \pm 16.44^{* * *}$ & 16.39 \\
\hline VAS-rest & $2.79 \pm 2.55$ & $1.72 \pm 1.96^{* *}$ & 38.35 & $3.43 \pm 2.74$ & $2.40 \pm 2.27^{* * *}$ & 30.02 & $3.19 \pm 3.04$ & $1.91 \pm 2.18^{* * *}$ & 40.12 \\
\hline VAS-Walk & $5.36 \pm 2.50$ & $4.17 \pm 2.44^{* * *}$ & 22.2 & $5.80 \pm 2.51$ & $4.33 \pm 2.72^{* * *}$ & 25.34 & $5.86 \pm 2.78$ & $4.06 \pm 2.46^{* * *}$ & 30.72 \\
\hline VAS-up & $7.33 \pm 1.66$ & $5.97 \pm 1.97^{* * *}$ & 18.55 & $7.23 \pm 2.24$ & $5.70 \pm 2.36^{* * *}$ & 21.16 & $7.25 \pm 2.18$ & $4.86 \pm 2.38^{* * *}$ & 32.96 \\
\hline VAS-down & $6.81 \pm 2.58$ & $5.38 \pm 2.53^{* * *}$ & 20.99 & $7.27 \pm 2.49$ & $5.47 \pm 2.80^{* * *}$ & 24.75 & $7.00 \pm 2.40$ & $4.86 \pm 2.32^{* * *}$ & 30.57 \\
\hline $\begin{array}{l}\text { 6-min walk } \\
\text { distance(m) }\end{array}$ & $209.25 \pm 54.9$ & $238.05 \pm 51.3^{* * *}$ & 13.76 & $211.5 \pm 83.7$ & $241.65 \pm 67.5^{* * *}$ & 14.25 & $239.4 \pm 71.1$ & $253.8 \pm 64.8^{*}$ & 6.01 \\
\hline
\end{tabular}

BMI: body mass index, SBP: systolic blood pressure, DBP: diastolic blood pressure, PR: pulse rate, RR: Respiratory rate, WGS: WOMAC global score, WOMAC: Western Ontario and McMaster Universities Osteoarthritis Index, PF: Physical function, VAS: visual analog scale.

\section{Outcome Measures}

All participants were assessed for primary and secondary outcomes twice, at baseline (day 1) and end of study period, day 7 .

\section{Primary outcomes}

i. Visual Analog Scale (VAS): The visual analogue scale is a psychometric response scale which was used to assess pain on climbing stairs (20 staircases), climbing down from stairs (20 staircases) as well as following 6 min walking on flat surface. It was be used as an instrument to measure subjective quantification of pain. When responding to a VAS item, respondents was be asked to specify their level of pain by indicating a position along a continuous line between two endpoints.

ii. WOMAC: The WOMAC has been extensively evaluated in populations suffering from osteoarthritis (N Bellamy, Buchanan, Goldsmith, Campbell, \& Stitt, 1988). The Indian version of WOMAC was used to assess the disability and quality of life [5]. Western Ontario and McMaster Universities Secondary Osteoarthritis index (WOMAC) is widely used in the evaluation of Hip and Knee Osteoarthritis. It is a self-administered questionnaire consisting of 24 items divided into 3 subscales assess the three dimensions of pain, disability and joint stiffness in knee and hip osteoarthritis [6].
Secondary outcome measures: Anthropometric Measurements
i. Height: Was measured in Centimeters (cm)
ii. Weight
iii. BMI: 6- min walk test
iii. BMI
iv. 6-min walk test

\section{Discussion}

\section{Modus operandi of yoga and naturopathy therapy}

Possible mechanism of improvement in yoga and naturopathy group is detoxification treatment, diet restriction and physical activity which help them more in reducing pain and improve the physical functioning. Yoga and naturopathy integrated therapies 
are found to reduce inflammatory markers in patients with chronic inflammatory disorders [7]. This could be the mechanism of action for improvement in the outcomes of OA knees through Yoga and Naturopathy.

\section{Modus operandi of ayurveda therapy}

The possible mechanism of action behind reduction of all the symptoms is due to medicated oil application frequently but the long-term effects of such applications need to be studied Ayurveda and Naturopathy therapies was planned by respective doctors.

\section{Conclusion}

Although statistically insignificant, the current study revealed that integration of naturopathy to yoga therapy was effective in reducing weight, and pain, whereas integrating Ayurveda to yoga therapy could lead to better reduction in stiffness in patients with OA knees. Such non-significant trends could be tested using larger sample size with prolonged intervention period in future studies.

\section{Strength of The Study}

The strengths of the study are:

a) This multidisciplinary study encompasses the fields of yogic science, Ayurveda and Naturopathy.

b) No earlier study has reported integration of yoga with Ayurveda and naturopathy for OA knees.

c) Because the duration of intervention was short, acceptability and adherence to therapy was good d) As integration were delivered through a standard protocol, it could be reproduced in the exact way for all cases.

\section{References}

1. Martel Pelletier J, Pelletier JP (2010) Is osteoarthritis a disease involving only cartilage or other articular tissues? Eklem Hastaliklari ve Cerrahisi 21(1): 2-14.

2. Umlauf D, Frank S, Pap T, Bertrand J (2010) Cartilage biology, pathology, and repair. Cellular and Molecular Life Sciences 67(24): 4197-4211.

3. Goldring SR, Goldring MB (2006) Clinical aspects, pathology and pathophysiology of osteoarthritis. Journal of Musculoskeletal \& Neuronal 122 Interactions 6(4): 376-378.

4. Heijink A, Gomoll AH, Madry H, Drobnič M, Filardo G, et al. (2012) Biomechanical considerations in the pathogenesis of osteoarthritis of the knee. Knee Surgery Sports Traumatology Arthroscopy 20(3): 423435 .

5. Das SK, Mishra K, Ramakrishnan S, Srivastava R, Agarwal GG, et al. (2002) A randomized controlled trial to evaluate the slow acting symptom modifying effects of a regimen containing colchicine in a subset of patients with osteoarthritis of the knee. Osteoarthritis and Cartilage 10(4): 247-252.

6. Baron G, Tubach F, Ravaud P, Logeart I, Dougados M (2007) Validation of a short form of the Western Ontario and McMaster Universities Osteoarthritis Index function subscale in hip and knee osteoarthritis. Arthritis \& Rheumatism 57(4): 633-638.

7. Bellamy N, Buchanan WW, Goldsmith CH, Campbell J, Stitt LW (1988) Validation study of WOMAC: a health status instrument for measuring clinically important patient relevant outcomes to antirheumatic drug therapy in patients with osteoarthritis of the hip or knee. The Journal of Rheumatology 15(12): 1833-1840.
This work is licensed under Creative Commons Attribution 4.0 License

To Submit Your Article Click Here: $\quad$ Submit Article

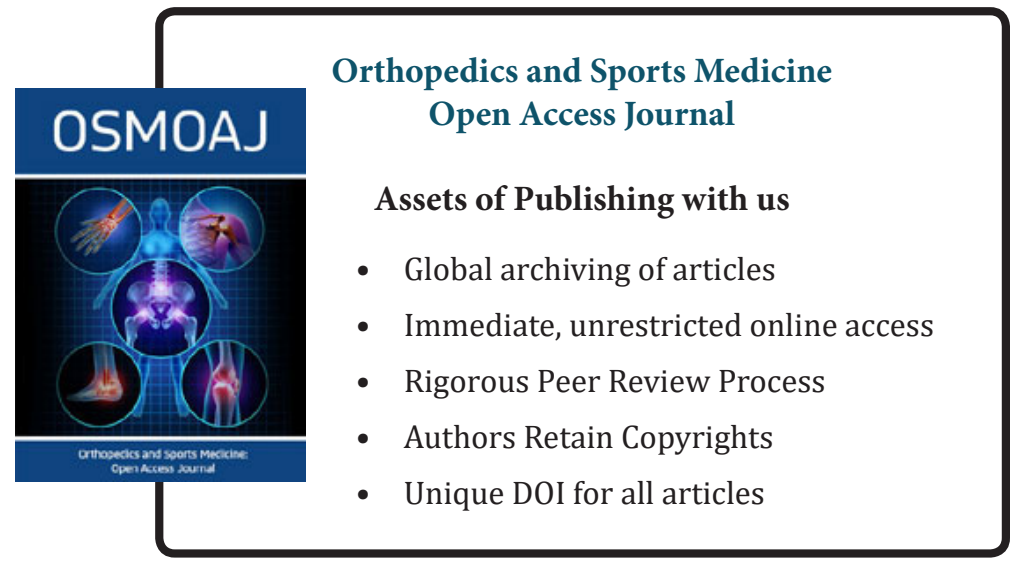

